\title{
Morphological and Physio-biochemical Changes in Response to Foliar Application of Brassinosteroid and Water Stress in Apple Plants Under Pot Culture Study
}

\author{
Sudarshna Kumari ${ }^{{ }^{*}}$ and Anju Thakur ${ }^{2}$
}

${ }^{1}$ Dept. of Plant Physiology, G. B. Pant University of Agriculture and Technology, Pantnagar, US Nagar, Uttrakhand (263 145), India ${ }^{2}$ Dept. of Basic Sciences (Plant Physiology), Dr. Y. S. Parmar University of Horticulture and Forestry, Nauni, Solan, Himachal Pradesh (173 230), India

\section{Corresponding Author}

Sudarshna Kumari

e-mail: sudarshnakumari89@gmail.com

\author{
Article History \\ Article ID: AR1944 \\ Received in $31^{\text {st }}$ December, 2018 \\ Received in revised form $02^{\text {nd }}$ January, 2019 \\ Accepted in final form $10^{\text {th }}$ February, 2019
}

\begin{abstract}
The cultivated apple (Malusxdomestica Borkh.), a member of family Rosaceae andsub-family Pomoideae, is native to South West Asia. The primary centre of origin of apple is thought to be the region, which includes the Asia Minor, the Caucasus, Soviet Central Asia and Himalayan India and Pakistan. Apple occupies a significant place in the horticultural wealth of Himachal Pradesh cultivated commercially in most countries in the temperate region of the world and in some tropical areas with high altitude. This study was undertaken to identify morphological and physio-biochemical changes in one-year-old grafted apple young seedling plants of two varieties of Super Chief and Red chief under 15 and 30 days of induced water stress followed by $0.05 \mathrm{ppm}$ brassinosteroid and $0.1 \mathrm{ppm}$ brassinosteroid. The maximum reduction in growth parameters was registered by plants subjected to 30 of water stress as compared to 15 days of water stress. Osmoregulating substances i.e. total free amino acid and total soluble sugars showed increased accumulation and enhanced activities of antioxidant enzyme catalase with increasing duration of water stress, which helped in enhancing drought tolerance. However, brassinosteroid at both concentrations could help in maintaining vital growth and biochemical processes under water stress conditions. Foliar spray of brassinosteroid ( $0.05 \mathrm{ppm}$ ) prior to imposition of stress can pave the way to minimize the deleterious effects of water stress on apple plants.
\end{abstract}

Keywords: Apple, brassinosteroid, physio-biochemical, plant growth, water stress

\section{Introduction}

In India, the cultivation of apple is largely done in Jammu and Kashmir, Himachal Pradesh and Uttrakhand, however, it is also cultivated in Arunachal Pradesh, Nagaland and Meghalaya. The apple occupies a prominent position with respect to area and production among the temperate fruits in India. The area under apple increased from 3025 hectares during 19601961 to 277, 000 hectares during 2016-2017, consequently, the production has also increased from 1200 t to 2242, 000 t (NHB, 2016). In the Himachal Pradesh, it is cultivated on 110679 hectares area with the total production of 777126 t (Anonymous, 2016). In Himachal Pradesh, Apple is mainly grown under rainfed conditions. Moreover, the rainfall is not well distributed throughout the year. Most of the rainfall is received during the monsoon and winter seasons and there is very less or no rains during critical periods of growth and development (Singh et al., 2016). Thus, the soil moisture generally remains very low during the summer months and a water stress condition develops (Devi et al., 2013). Drought stress is one of the most adverse factors of plant growth and productivity and considered a severe threat for sustainable crop production in the conditions of changing the climate. Drought triggers a wide variety of plant responses, ranging from cellular metabolism to changes in growth rates and crop yields. Understanding the biochemical, physiological and molecular responses to drought is essential for a holistic perception of plant resistance mechanisms to drought-induced changes at morphological, physiological and biochemical levels. One of the most promising roles of brassinosteroid is their ability to confer resistance to a wide array of abiotic stresses. Stress protective action of brassinosteroids is the result of a complex sequence of biochemical shifts, such as activation or suppression of key enzymatic reactions, induction of protein synthesis and the production of various chemical defence compounds. The fact that brassinosteroid is natural, non-toxic and eco-friendly products, which when applied in extremely low doses are capable of improving crop yield even in non-fertilized fields, this makes them suitable for use in agriculture and ecology, especially under abiotic stress conditions (Ali et al., 2018). 


\section{Materials and Methods}

The experiment was conducted at an elevation of 1250 $\mathrm{m}$ above mean sea level at $30^{\circ} 51^{\prime} \mathrm{N}$ latitude and $76^{\circ} 11^{\prime} \mathrm{E}$ longitude in the Department of Fruit Science, Dr Yashwant Singh Parmar University of Horticulture and Forestry, Nauni, Solan, Himachal Pradesh. The experimental orchard lies under the sub-temperate, sub-humid mid-hill agro-climatic zone II of Himachal Pradesh where, summer is moderately hot during May-June while, winter is quite severe during December-January. The annual rainfall ranges between $110-120 \mathrm{~cm}$ and the major amount of which is received from mid-June to September. The suitable methodology has been used to understand the response of apple seedlings to different levels of imposed conditions of water stress alone and in combination with different concentrations of brassinosteroid under controlled conditions. One-year-old seedlings of apple varieties i.e. Super chief and Red chief were planted in plastic pots of $85 \times 30 \mathrm{~cm}^{2}$ (diameter $\times$ height) and filled with soil and FYM (3:1). Planting was done under natural condition, in the first week of February 2016. Various treatments comprised of control (No water stress); water stress for 15 days; brassinosteroid 0.05 ppm followed by 15 days water stress; brassinosteroid $0.10 \mathrm{ppm}$ followed by 15 days water stress; control (To compare 30 days water stress); water stress for 30 days; brassinosteroid 0.05 ppm followed by 30 days water stress; brassinosteroid 0.10 ppm followed by 30 days of water stress.

Water stress conditions were imposed by withholding watering for 15 and 30 days respectively. Before subjecting plants of both varieties to water stress conditions, pots were brought to the field capacity. Well-watered control was maintained at nearly field capacity for comparison. The plants were allowed to experience water stress conditions for 15 and 30 days withholding water. Observations regarding growth parameters, viz. plant height and leaf area were recorded according to standard procedures and photosynthetic rate with LICOR-6200 portable photosynthesis system during the study. The total free amino acid content in leaves of the same age of unstressed and stressed plants was estimated by the method described by Lee and Takahasi, 1996. Proline content was estimated by the method of Singh et al., 1972. Two $g$ fresh material i.e. leaves of same age after 15 and 30 days from control and stressed plants were taken and homogenized with $10 \mathrm{ml}$ of methanol: chloroform: water in 12:5:1 ratio and centrifuged at $5000 \mathrm{rpm}$ for $15 \mathrm{~min}$. Final volume was made exactly $10 \mathrm{ml}$ after centrifugation. Thereafter, supernatant was taken in a separating funnel and $6 \mathrm{ml}$ of chloroform with $4 \mathrm{ml}$ of water was added to it and mixed thoroughly and kept as such for $5 \mathrm{~min}$. Lower layer of pigment was discarded, whereas the upper layer was taken and final volume was made up to $10 \mathrm{ml}$ with distilled water. This served as the extract for estimation of proline.Same procedure for extraction of peroxidase Abohatem et al. (2011). Data on plant growth and biochemical characteristics of apple cultivars to determine the significance of differences were analyzed by using Completely Randomized Design (CRD) with three replications. All data were subjected to two way factorial ANOVA carried out using the SPSS computer package (SPSS Inc. USA).

\section{Results and Discussion}

All the growth characteristics viz. plant height, leaf area, photosynthetic rate, canopy temperature depression, total free proline, total free amino acids and peroxidase were found higher for 30 days duration as compared to 15 days duration in both varieties viz. Super chief and Red chief. Among treatments, all growth parameters were maximum in control i.e. unstressed plants, whereas minimum in water stress alone. Maximum per cent reductions in plant height (13.73 and $15.57 \%$ ) were observed in plants subjected to 30 days of water stress, whereas minimum reductions i.e. 4.29 and $4.91 \%$ were registered by brassinosteroid $0.05 \mathrm{ppm}$ under 15 days of water stress below control in Super chief and Red chief, respectively (Figure 1). Highest per cent reductions in leaf area were 12.91 and $14.20 \%$ in plants subjected to 30 days of water stress, whereas lower reductions 2.21 and $2.82 \%$ were registered by brassinosteroid 0.05 ppm under 15 days of water stress below control in Super chief and Red chief, respectively (Figure 2). Maximum photosynthetic rates (11.62 and $10.93 \mu \mathrm{mol} / \mathrm{m}^{2} / \mathrm{s}$ ) were observed in control after 30 days, whereas minimum photosynthetic rates i.e. 6.61 and 7.01 $\mu \mathrm{mol} / \mathrm{m}^{2} / \mathrm{s}$ were recorded in plants subjected to 30 days of water stress. Brassinosteroid $0.05 \mathrm{ppm}$ showed photosynthetic rates ( 8.45 and $\left.8.32 \mu \mathrm{mol} / \mathrm{m}^{2} / \mathrm{s}\right)$ under 30 days of water stress in varieties Super chief and Red chief respectively (Figure 3). Canopy temperature depression showed maximum per cent reductions ( 44.20 and $38.65 \%$ below control) in plants subjected to 30 days of water stress, whereas minimum reductions ( 56.42 and $53.80 \%$ below control) were registered by brassinosteroid 0.05 ppm under 15 days of control for Super chief and Red chief respectively (Figure 4).

Biochemical characteristics i.e. total free proline, total free amino acids, and peroxidase was significantly higher for 30

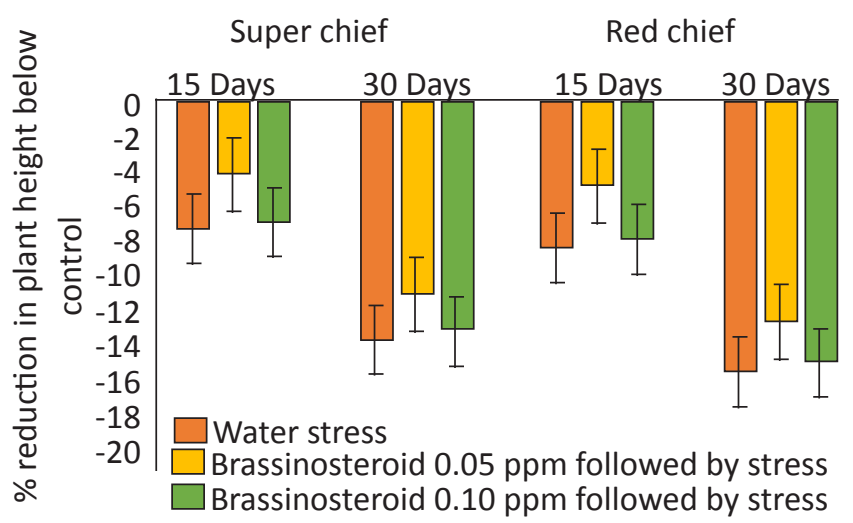

Figure 1: Per cent reduction in plant height of water stressed apple plants.Vertical bar represent mean of three replication \pm SEm and LSD $(p \leq 0.05)$ 


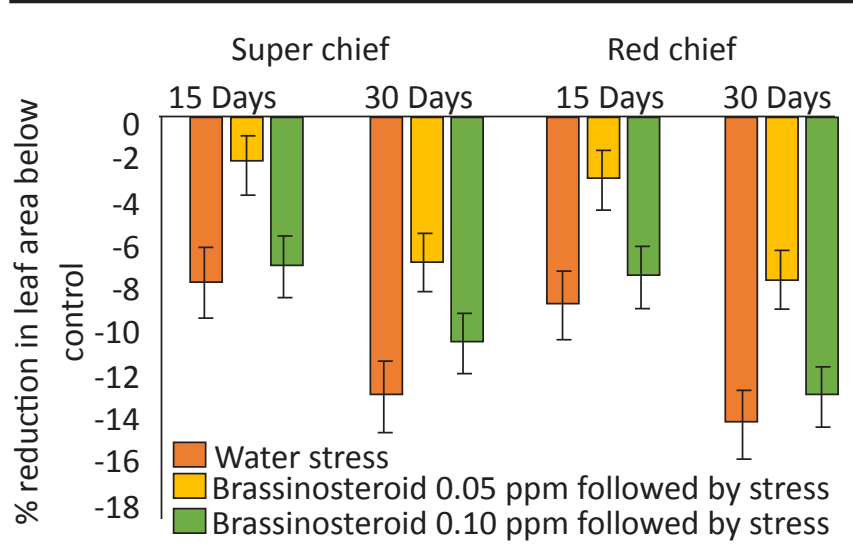

Figure 2: Per cent reduction in leaf area of water stressed apple plants.Vertical bar represent mean of three replication \pm SEm and LSD $(p \leq 0.05)$

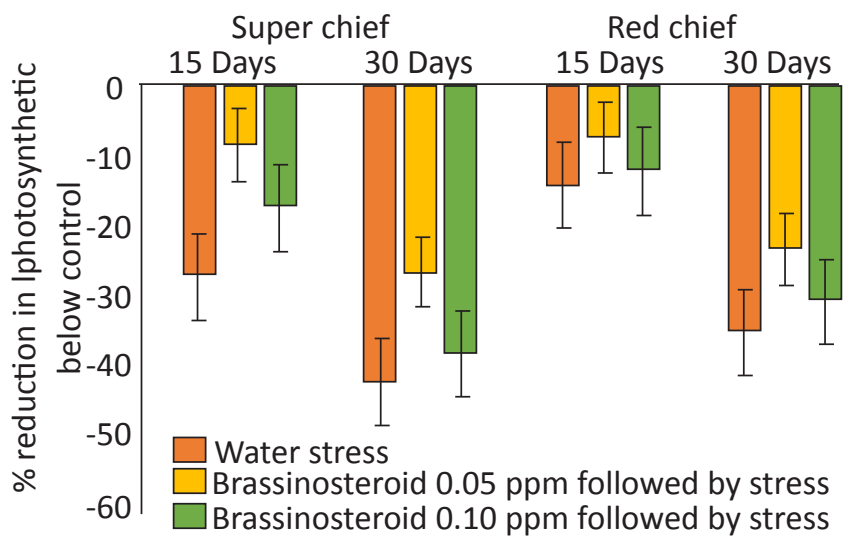

Figure 3: Per cent reduction in photosynthetic rate of water stressed apple plants. Vertical bar represent mean of three replication \pm SEm and LSD $(p \leq 0.05)$

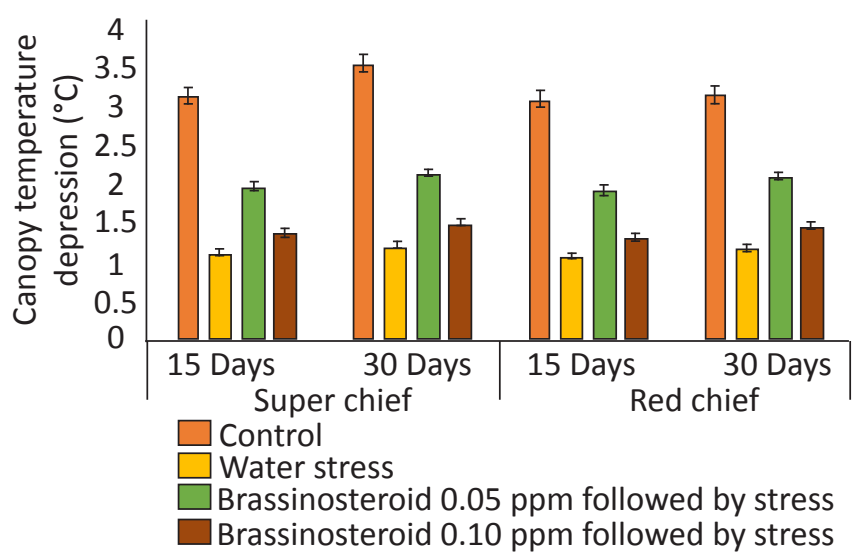

Figure 4: Canopy temperature depression $\left({ }^{\circ} \mathrm{C}\right)$ of water stressed apple plants. Vertical bar represent mean of three replication \pm SEm and LSD $(p \leq 0.05)$

days duration and lower for 15 days duration in varieties viz. Super chief and Red chief respectively. Among treatments maximum accumulation of total free proline, total free amino acids and soluble sugars were registered in water stress alone, whereas minimum was recorded for unstressed plants (control) for both the cultivars. In variety Super chief and Red chief maximum free amino acid content (57.65 and 58.51 $\mathrm{mg} \mathrm{g}^{-1}$ respectively) (Figure 5) and total free proline ( 36.70 and $36.95 \mathrm{mg} \mathrm{g}^{-1}$ respectively) were recorded for 30 days of water stress (Figure 6). However, lesser accumulation of these substances was recorded under 15 days of unstressed plants, which were closely followed by brassinosteroid $0.05 \mathrm{ppm}$ in both varieties. The activities of enzymes were significantly affected by water stress treatments. Maximum per cent increased in peroxidase (119\% above control) were registered by brassinosteroid $0.05 \mathrm{ppm}$ under 30 days of water stress, whereas minimum activity was observed in variety Super chief and Red chief respectively (Figure 7). Brassinosteroid helped in enhancing the activities of antioxidant enzymes over the activities in stressed plants. Maximum soil moisture content was recorded for control i.e. 30.50 and $30.66 \%$ after 30 days, whereas minimum soil moisture content 9.82 and $9.73 \%$ was recorded for 30 days of stress in Super chief and Red chief respectively (Figure 8). Brassinosteroid 0.05 and $0.10 \mathrm{ppm}$ showed higher soil moisture content than water stress alone.

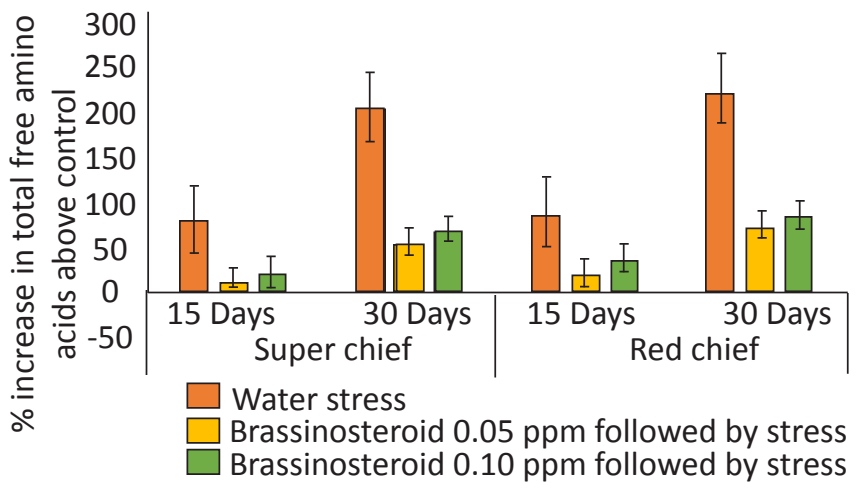

Figure 5: \% increase in total free amino acids of water stressed apple plants. Vertical bar represent mean of three replication \pm SEm and LSD $(p \leq 0.05)$

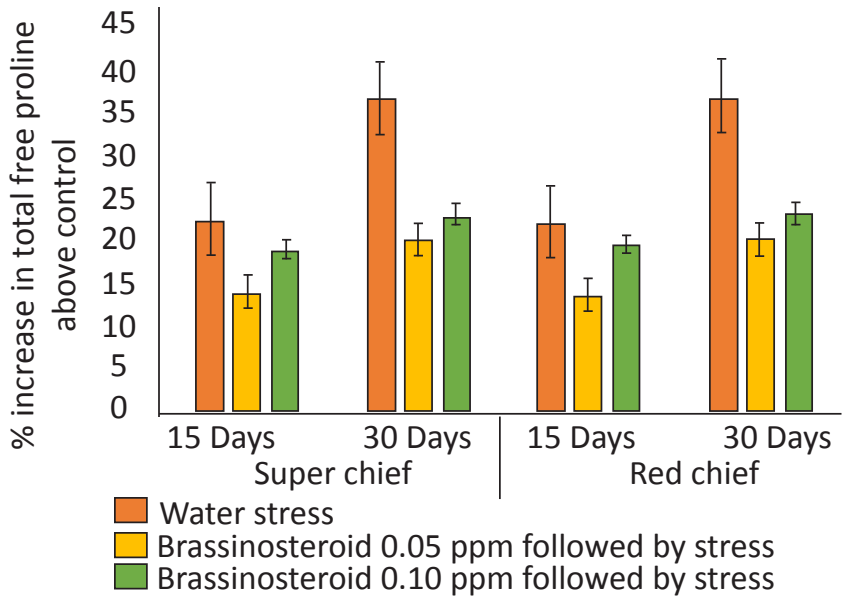

Figure 6: \% increase in total free proline of water stressed apple plants. Vertical bar represent mean of three replication \pm SEm and LSD $(p \leq 0.05)$ 


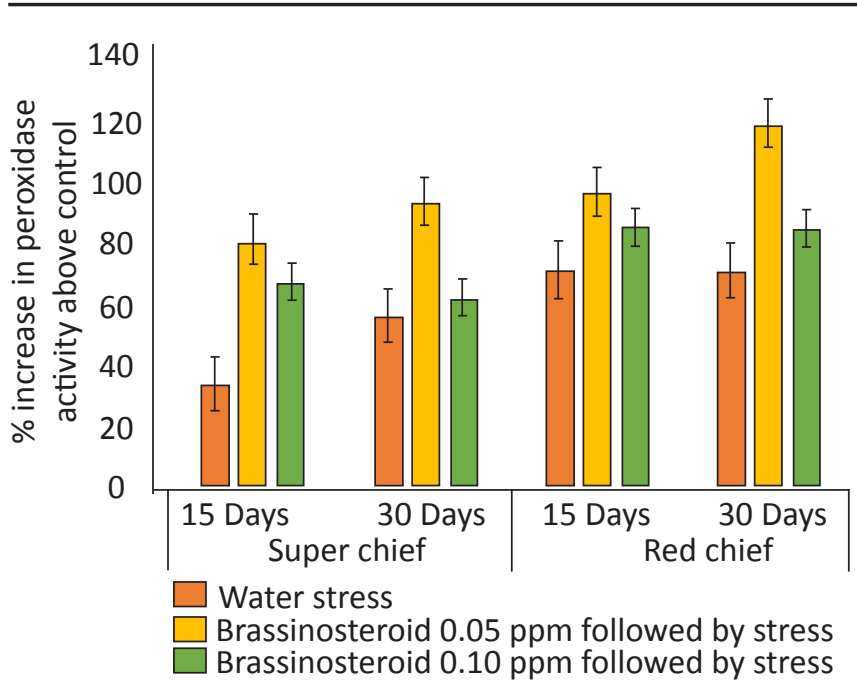

Figure 7: Per cent increase in peroxidase activityof water stressed apple plants. Vertical bar represent mean of three replication \pm SEm and LSD $(p \leq 0.05)$

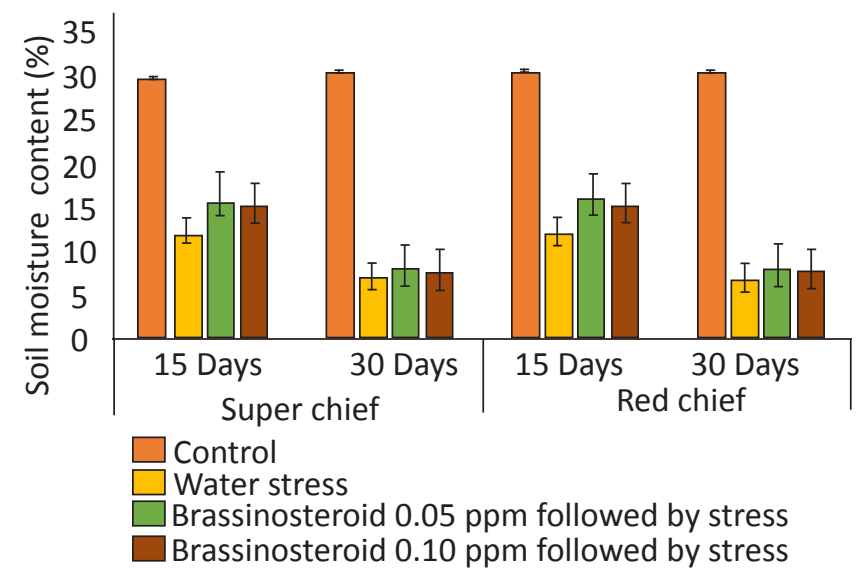

Figure 8: Soil moisture (\%) content of water stressed apple plants. Vertical bar represent mean of three replication $\pm S E m$ and LSD $(p \leq 0.05)$

Both the varieties of apple i.e. Super chief and Red chief were equally sensitive to water stress and brassinosteroid.

During the course of the present investigation, the plant growth and physio-biochemical parameters were significantly influenced both by treatments as well as durations in oneyear-old plants of both varieties viz. Super chief and Red chief. Water stress suppresses the photosynthesis by reducing the leaf area, closing the stomata and checking the activity of dehydrated protoplasmic machinery (Taizand Zeiger, 1998). Alleweldtand Ruhl, (1982) also reported 33 to $48 \%$ reduction in photosynthetic rate in plants grown under water stress conditions. Boyer, (1976) noted that photosynthesis was partially or completely inhibited by water stress, but prolonged water deficits resulted in photosynthetic acclimation to water stress. The linear correlation between photosynthesis and stomatal conductance in apple trees under water stress might be responsible for the reduction in leaf area and photosynthetic rate (Davies and Lakso, 1979). Water limitation has numerous effects on photosynthesis that have been reported extensively. The initial effect of water limitation on photosynthesis is usually due to stomatal closure, which may close because of root signal because of low turgor pressure in guard cells. Non-stomatal inhibition of photosynthesis during water stress normally accounts for a larger proportion of photosynthetic inhibition as water potential becomes lower. All these inhibitions may occur concurrently (Osmond and Grace, 1995). Our studies indicated that brassinosteroid at both concentrations was found beneficial in contracting the deleterious effects of water stress on physiological parameters.

Water stress for 15 and 30 days led to the reduction in canopy temperature depression with a higher reduction in 30 days stressed plants. Pretreatment with brassinosteroid both at 0.05 and $0.10 \mathrm{ppm}$ concentrations before imposing water stress resulted in reversing the effects of water stress by maintaining higher values of CTD as compared to stress. Thus, brassinosteroid was found beneficial in minimizing the deleterious effects of water stress on apple varieties i.e. Super chief and Red chief. In general, CTD has been used to assess plant water relationship because it represents an overall, integrated physiological response to drought and high temperature. CTD is affected generally by biological and environmental factors like water status of soil, wind, evapotranspiration, cloudiness, plant metabolism, air temperature and relative humidity (Reynolds et al., 2001). Higher CTD is a desirable parameter since it reflects the cooler canopies, which help in maintaining the proper balance between anabolic and catabolic processes and in minimizing the deleterious effects of water stress. Therefore, the canopy temperature depression also reflects the need for irrigation. Higher canopy temperature lower CTD is common in waterstressed plants (Helyes et al., 2006).

Our studies revealed that total free proline, total free amino acids, accumulated substantially at the advent of water stress in both the varieties i.e. Super chief and Red chief. In variety Super chief and Red chief maximum proline accumulation i.e. 36.70 and $36.95 \%$ respectively were registered by waterstressed plants. Proline accumulation is in agreement with the findings of earlier workers who have observed a significant increase in proline content at the advent of water deficit (Devi et al., 2013). Accumulation of proline in plant tissues is a clear marker for environmental stress, particularly in apple plants under drought stress (Yanbao et al., 2006). Proline is mainly a cytoplasmically compatible osmotic substance and highly soluble in water. So, higher accumulation of proline during water stress helps the plants to maintain higher internal water content by affecting osmotic potential $\left(\Psi_{\mathrm{s}}\right)$, a component of water potential, thus resulting in better drought adaptability. Proline and total free amino acids are often increased in water-stressed leaves. Proline act as an organic osmoregulator that can improve the drought resistance of plants (Yoshiba et al., 2006). There are several reports of an increase in sugars 
solution and proline in apple under drought stress. Jie et al., (2010) reported that under drought stress proline at high levels was accumulated in different organs of apple. The role of proline in the adaptation and survival of plants under drought stress was reported by Watanabe et al. (2000). Osmotic adjustment through the accumulation of cellular solutes, such as prolinehas been suggested as one of the possible means for overcoming the osmotic stress caused by the loss of water (Mccueand Hanson, 1990) in apple plants. High level of proline enables the plants to maintain low water potentially causing the accumulation of compatible osmolytes that allows additional water to be taken up from the environment, thus causing a buffering effect of water deficit within the organism (Mousaand Abdel Aziz, 2008). Underwater stress, proline concentration can reach up to $80 \%$ of the total amino acid pool. The biochemical defence system against abiotic stress involves the amino acid proline (an osmolyte) which acts as cellular protectors largely accumulated in several plant species in response to abiotic stress and scavenge reactive oxygen species (Ashraf and Foolad, 2007). Proline also serves as a sink for energy to regulate redox potentials, a hydroxyl radical scavenger (Sauterand Dietz, 2002), a solute that protects the macromolecules against denaturation as a means for reducing acidity in the cell. In addition, our studies have also indicated substantial increase in soluble sugar content up to $69.34 \%$ over the control as well as total free amino acids content up to $125 \%$ over the control in plants subjected to 30 days of water stress as compared to 15 day stress duration, which can play an important role to overcome the deleterious effects of water stress in varieties Super chief and Red chief. Several investigators have reported the increase in soluble sugars with increasing water stress (Murakeozy et al., 2003). Accumulation of sugars has a direct connection with the physiological process such as photosynthesis, materials transfer and respiration (Pinheiro et al., 2004). Accumulation of free amino acid content in leaves of water deficit plants induced by water stress plays an important role in osmoregulation. Rai et al. (2003) observed that survival and growth of plants in water stress conditions is the result of adaptation processes such as ion transport; compartmentation of an osmotic solute; synthesis and their accumulation, which leads to the osmotic adjustment and protein, turn over for cellular repair. The increased accumulation of amino acid content is valued in response to osmotic stress since the early accumulation of free amino acid content can contribute to a greater level of stress tolerance.

Brassinosteroids resulted in the enhanced accumulation of osmolytes i.e. amino acids and proline. Osmolytes play a significant protective role in plant responses to water stress and resistance. Farooq et al. (2009) also observed that the application of BRs increased the free proline levels in rice under drought stress. The findings of the present investigation suggest that BRs are playing a positive role in combating water stress by enhancing the levels of osmoprotectants, metabolites and the activities of enzymes in both cultivars. Our studies revealed that activity of enzymes i.e. catalase and peroxidase were significantly influenced both by treatments and durations in both the varieties i.e. Super chief and Red chief. Maximum peroxidase activity was observed for 30 days of stress which was followed by pretreatment with brassinosteroid 0.05 and $0.10 \mathrm{ppm}$ before imposing water stress than control i.e. unstressed plants. The findings are in conformity with those of Anuradhaand Rao (2001) who observed that exogenous application of brassinosteroid resulted in enhanced tolerance to abiotic stresses in rice. The mitigation of water stress by brassinosteroid was associated with increased scavenging activity and removal of reactive oxygen species as reflected by elevated activities of antioxidant enzymes and peroxidase. In general, oxidative stress can cause the eventual death of plants due to excessive $\mathrm{H}_{2} \mathrm{O}_{2}$ accumulation. Since stress factors provoke enhanced production of $\mathrm{H}_{2} \mathrm{O}_{2}$ - metabolizing enzymes such as superoxide dismutase, catalase, ascorbate peroxidase, peroxidase and glutathione sulfotransferases (Sofo et al., 2015). Phytotoxicity from water stress is closely related to the production of reactive oxygen species in plants. An imbalance between ROS production and ROS scavenging leads to oxidative burst. ROS can react with lipids, DNA and proteins, and causes membrane damage and enzyme inactivation resulting in inhibition of plant growth (Mittler, 2002). In order to scavenge ROS and to counter oxidative stress, plants evolved an efficient antioxidant defence system. In our studies, the increase in the activity of peroxidase and catalase enzyme in stressed plants pretreated with brassinosteroid seems to cope with the harmful effects of water stress. However, it is observed that pants pre-treated with brassinosteroid 0.05 and $0.10 \mathrm{ppm}$ could maintain the significantly higher activity of peroxidase and catalase in stressed plants. These findings are in conformity with those of Bajguz and Hayat (2009) who reported that BRs could regulate antioxidant enzymes such as catalase etc. in plants under different stress conditions. Fariduddin et al. (2009) also showed that 28- homobrassinoloid treatment could elevate antioxidant system including the peroxidase, catalase etc. in Brassica juncea.

\section{Conclusion}

Water stress for 15 and 30 days led to the reduction in growth characteristics with a higher reduction in 30 days stressed plants. Pretreatment with brassinosteroid both at 0.05 and $0.10 \mathrm{ppm}$ concentration prior to imposing water stress helped in minimizing the deleterious effects of water stress on apple varieties i.e. Super chief and Red chief.

\section{Acknowledgement}

Authors are highly thankful to the facilities and funds provided by Dr. Yashwant Singh Parmar University of Horticulture and Forestry, Nauni, Solan 173230 (H.P.) India. 


\section{References}

Abohatem, M., Zouine, J., Harami, I.E., 2011. Low concentration of BAP and high rate of subcultures improve the establishment and multiplication of somatic embryos in date palm suspension cultures by limiting oxidative browning association with high levels of totalphenols and peroxidase activities.Scientia Horticulturae 130, 344-348.

Ali, A., Yumei, L., Rongrong, D., Longqiang, B., Xianchang, Y., Yansu, L., 2018. The physiological and molecularmechanism of brassinosteroid in responseto stress: a review.Biological Research 51(46), 1-16.

Alleweldt, C., Ruhl, E., 1982. UntersuchungenZumGaswechsel der Rebe. Vitis. Acta Horticulturae 171, 305-314.

Anonymous, 2016. Administrative report of Directorate of Horticulture. Navbhahar, Chotta Shimla, Shimla-171002, Himachal Pradesh, India, http://www.hpagrisnet.gov.in.

Anuradha, S., Rao, S.S.R., 2001. Application of brassinosteroids to rice seeds (Oryza sativa) reduced the impact of salt stress on growth, prevented photosynthetic pigment loss and increased nitrate reductase activity. Plant Growth Regulators 40, 29-32.

Ashraf, M., Akram, A.N., Arteca, R.N., Foolad, M.R., 2010. The physiological, biochemical and molecular roles of brassinosteroids and salicylic acid in plant processes and salt tolerance. Critical Reviews in Plant Sciences 29, 162-190.

Bajguz, A., Hayat, S., 2009. Effects of brassinosteroids on the plant responses to environmental stresses. Plant Physiology and Biochemistry 47, 1-8.

Boyer, J.S., 1976. Water deficits and photosynthesis. In: Kozlowski T.T. (editor). Water deficits and plant growth Vol. IV, Academic Press, New York, 153-190.

Davies, F.S., Lakso, A.N., 1979. Water relations in apple. Changes in water potential deficits and plant growth. Academic Press, New York, 153-190.

Devi, S., Chauhan, P.S., Thakur, D., 2013. Effect of clonal rootstocks on the stomatalconductance, transpiration rate, photosynthetic rateand leaf nutrient status of apple cultivars scarletgala and red fuji. The Asian Journal of Horticulture 8(2), 653-658.

Fariduddin, Q., Khripach, S., Hasan, S.A., Ali, B., Hayat, S., Ahmad, A., 2009. Effect of 28- homobrassinolide on the drought stress-induced changes in photosynthesis and antioxidant system of Brassica juncea L. Acta PhysiologiaePlantarum 31, 889-897.

Farooq, M., Wahid, A., Basra, S.M.A., Din, I.U., 2009. Improving the water relations and gas exchange with brassinosteroids in rice under drought stress. Journal of Agronomy and Crop Science 195, 262-269.

Helyes, L., Pek, Z., McMichel, B., 2006. Relationship between the stress degree-day index and biomass production and effect and timing of irrigation in snapbean (Phaseolus vulgaris). Acta BotanicaHungarica 48, 3-4.
Jie, Y.Y., John, G., Streeter, Ferree, D.C., 2010. Influence of soil drought stress on photosynthesis, carbohydrates and the nitrogen and phosphorus absorb in different section of leaves and stem of Fugi/M.9EML, a young apple seedling. African Journal of Biotechnology 9, 5320-5325

Lee, Y.P., Takashasi, T., 1966. An improved colorimetric determination of amino acids with the use of Ninhydrin. Analytical Biochemistry 14, 71-77.

Mccue, K.F., Hanson, A.D., 1990. Drought and salt tolerance: Towards understanding and application. Tibtech -December 8, 358-362.

Mittler, R., 2002. Oxidative Stress Antioxidants and Stress Tolerance. Trends in Plant Science 7, 405-410.

Mousa, H.R., Abdel-Aziz, S.M., 2008. Comparative response of drought tolerant and drought sensitive maize genotypes to water stress. Australian Journal Crop Sciences 1, 31-36.

Murakeozy, E.P., Nagy, Z., Duhaze, Couchereau, A.Z., 2003. Seasonal changes in the levels of compatible osmolytes in three halophtytic species of inland saline vegetation in Hungary. Journal of plant physiology 160, 395-401.

N.H.B., 2016. Annual production of fruits. National Horticulture Board, Ministry of Agriculture and Farmers Welfare, Government of India, 85, Institutional Area, Sector - 18, Gurugram-122015 (Haryana) http://www.nhb.gov.in.

Osmond, C.B., Grace, S.C., 1995. Perspective on photo inhibition and photo respiration in field: quintessential inefficiencies of light and dark reaction of photosynthesis. Journal Experimental Botany46, 1351-1362.

Pinheiro, C., Passarinho, J.A., Ricardo, C.P., 2004. Effect of drought and rewatering on the metabolism of Lupinus albus organs. Journal of plant physiology 161, 12031210.

Rai, S.P., Luthra, R., Kumar, S., 2003. Salt tolerant mutants in glycophytic salinity response (GRS) genes in Catharanthusroseus. Theoretical and Applied Genetics 106, 221-230.

Reynolds, M.P., Trethowan, R.T., Van, G.M., Rajaram, S., 2001. Application of physiology to wheat breeding. In: Reynolds, M.P., Ortiz-monasterio, I., Nab, M.C. (Eds.), Application of physiology in wheat breeding. Mexico, D F, CIMMYT.

Sauter, A., Dietz, K.J., Hartung, W., 2002. A possible tress physiological role of abscisic acid conjugates in root-toshoot signaling. Plant, Cell \& Environment 25, 223-228.

Singh, N., Sharma, D.P., Chand, H., 2016. Impact of climate change on apple production in India: A review. Current World Environment 11, 251-259.

Sofo, A., Scopa, A., Nuzzaci, M., Vitti, A., 2015. Ascorbate peroxidase and catalase activities and their genetic regulation in plants subjected to drought and salinity stresses. International Journal of Molecular Sciences 16, 13561-13578.

Taiz, L., Zeiger, E., 1998. Plant Physiology. Second edition, 
Sinauer Associates, treatments under the stress of the 1998 drought. Research Circular-ohio-Agricultural University of Horticulture and Forestry, Nauni, Solan.

Watanabe, S., Kojima, K., Ide, Y., Satohiko, S., 2000. Effects of saline and osmotic stress on proline and sugar accumulation in Populuseuphratica in vitro. Plant Cell, Tissue and Organ Culture 63, 199-206.

Yanbao, L., Chunying, Y., Chunyang, L., 2006. Differences in some morphological, physiological, and biochemical responses to drought stress in two contrasting populations of Populusprzewalskii. PhysiologiaPlantarum 127, 182-191. Yoshiba, Y., Kiyosue, T., Katagiri, T., Ueda, H., Mizoguchi, T., Yamaguchi, K., Shinozaki, Wada, K., Harada, Y., Yuling, J., Hongqiang, Y., Haizhou, Z., Wei Zhang, D., 2006. Promotion of proline accumulation in apple leaves by bioregulators. Acta Horticulturae, 774. 